\title{
Biotin Status of Epileptics ${ }^{a}$
}

\author{
KLAUS-HENNING KRAUSE ${ }^{b}$, JEAN-PIERRE BONJOUR, $^{c}$ \\ PETER BERLIT, ${ }^{b}$ AND WALTER KOCHEN ${ }^{d}$ \\ ${ }^{b}$ Neurologische Universitätsklinik \\ Voss-Str. 2 \\ D-6900 Heidelberg, Federal Republic of Germany \\ 'Department of Vitamin and Nutrition Research \\ F. Hoffmann-La Roche \& Co. Ltd. \\ CH-4002 Basel, Switzerland \\ ${ }^{d U n i v e r s i t a ̈ t s-K i n d e r k l i n i k}$ \\ Im Neuenheimer Feld 153 \\ D-6900 Heidelberg, Federal Republic of Germany
}

\section{INTRODUCTION}

Little is known on the biochemical reactions that are the basis for the mode of action of anticonvulsants in man. For sodium valproate, the increase in the concentration of $\gamma$-amino-butyric acid could be the mode of action.' In contrast to sodium valproate, all clinically used anticonvulsants contain a carbamide group, which in most cases is cyclic (FIG. 1). A possible common biochemical mechanism of action of these anticonvulsants could be the reduction of circulating folate, which also has a cyclic carbamide group, observed under anticonvulsant treatment. ${ }^{2}$ Biotin too has a cyclic carbamide group and has not been investigated in epileptics until now. This vitamin seems of interest for various reasons: it serves as the prosthetic group of pyruvate, propionyl-CoA, 3-methylcrotonyl-CoA and acetyl-CoA carboxylases and has a central function in the metabolism of carbon dioxide. Carbon dioxide is known to have an important influence on the seizure threshold. ${ }^{3}$ The biotin-dependent carboxylases are involved in the metabolism of some neurotransmitters. Our first results indicated a marked reduction of biotin in the plasma of epileptics under long-term therapy with anticonvulsants. ${ }^{4,5}$ Starting from this observation the following questions were investigated:

(1) Can the tendency of a reduced plasma biotin concentration be confirmed in a larger collective of epileptics? Are there connections between the amount, type, and serum level of the anticonvulsants used or between the type of epilepsy or seizure and the observed levels of biotin in plasma?

(2) Are there signs of a biochemical effect of the reduced biotin levels when concentrations of organic acids in urine and plasma are determined?

\section{BIOTIN LEVELS IN PLASMA UNDER LONG-TERM THERAPY WITH ANTICONVULSANTS}

\section{Patients and Methods}

Biotin plasma concentrations were determined by a microbiological assay, ${ }^{6,7}$ using Lactobacillus plantarum as a test organism in 404 patients (235 men, 169 women)

\footnotetext{
${ }^{a}$ Dedicated to Professor H. Gänshirt, Director of the Neurological Clinic, University of Heidelberg on the occasion of his 65 th birthday. This work was supported in part by Grant $\mathrm{Kr}$ $659 / 1$ from the Deutsche Forschungsgemeinschaft.
} 


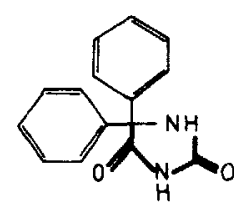

phenytoin

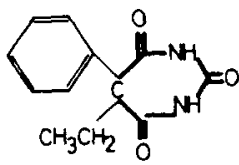

phenobarbital<smiles>CC1=CC=CC2CCCC2N1C(N)=O</smiles>

carbamazepine

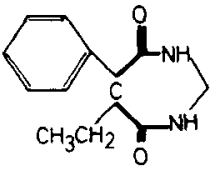

primidone<smiles>CCCC(CCC)C(O[Na])[N+](=O)[O-]</smiles>

sodium valproate<smiles>CN1C(=O)OC1(C)C</smiles>

trimethadione

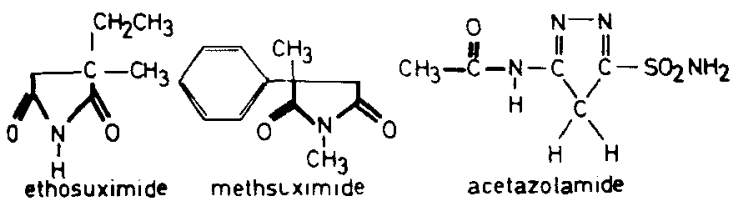

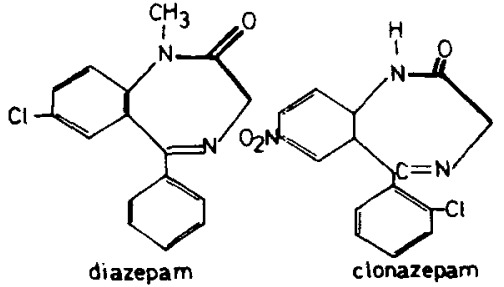<smiles>O=C(O)CC1SCC2NC(=O)NC21</smiles>

biotin

FIGURE 1. Chemical structure of commonly used anticonvulsants and of biotin (carbamid groups are marked by thick lines).

attending the Heidelberg out-patient clinic for epileptics. The patients were between 20 and 40 years oid. One-hundred and ninety-four patients had a partial and 210 a generalized epilepsy. Fifty-six patients showed partial seizures with elementary symptomatology, which were combined in part with tonic clonic seizures and/or partial seizures with complex symptomatology, 68 showed absences without known organic etiology and/or impulsive-petit-mal epilepsy, which mostly were combined with tonic-clonic seizures. At the time of examination 62 patients were treated in monotherapy with primidone (PRM), 40 with carbamazepine (CBZ), 39 with phenytoin (PHT), 21 with sodium valproate (VPA), and 14 with phenobarbital (PB). The other epileptics received a combined therapy with these or other anticonvulsants. Using equivalent units we calculated the average daily dose of anticonvulsants for each of these patients ( 1 equivalent unit $=50 \mathrm{mg}$ phenytoin, $30 \mathrm{mg}$ phenobarbital, $125 \mathrm{mg}$ primidone, $200 \mathrm{mg}$ carbamazepine, $250 \mathrm{mg}$ ethosuximide, $300 \mathrm{mg}$ sodium valproate, $50 \mathrm{mg}$ mesantoin, $2 \mathrm{mg}$ clonazepam, $300 \mathrm{mg}$ mesuximide, $100 \mathrm{mg}$ sulthiame, or 250 mg oxazolidine). The plasma levels of phenytoin, phenobarbital, primidone, carbamazepine, and sodium valproate were determined by gas chromatography or by enzymatic immunoassay. The patients were clinically tested especially in view of possible cerebellar dysfunctions or dermatological disturbances. One-hundred and twelve persons were used as controls ( 24 volunteers of the clinic staff, 40 blood donors 
and 48 patients with dermatological diseases, who had shown no differences in biotin levels compared with a normal population ${ }^{8}$ ); the mean age of the controls was $42.3 \pm$ 14.5 years, 67 were male and 45 female. Student's t-test was used for the comparison of biotin concentrations between patients with generalized and partial epilepsy and between patients with absences and partial seizures with elementary symptomatology, for the comparison of biotin values of patients with low or high average daily anticonvulsant doses, and for the comparison of biotin levels of epileptics with or without cerebellar signs. Connections between biotin concentrations in plasma and average daily dose or serum concentrations of anticonvulsants in patients under monotherapy were evaluated by linear regression analysis. The patients on monotherapy with phenytoin, carbamazepine, primidone, phenobarbital, or sodium valproate as well as patients with or without dermatological disturbances were compared using variance analysis.

\section{Results}

The mean biotin plasma concentration of the 404 long term-treated epileptics was $0.90 \pm 0.29 \mathrm{nmol} / 1$. This value is significantly $(p<0.0005)$ lower than the $1.63 \pm 0.49$ $\mathrm{nmol} / \mathrm{l}$ found in the control group (FIG. 2). The 210 patients with generalized epilepsy showed higher biotin values $(0.94 \pm 0.27 \mathrm{nmol} / \mathrm{l})$ than the 194 patients with partial epilepsy $(0.86 \pm 0.30 \mathrm{nmol} / 1 ; p<0.005)$ (FIG. 3$)$. The latter had a higher average daily intake of anticonvulsants $(7.54 \pm 3.25$ equivalent units/d) than the former $(6.92 \pm 3.07$ equivalent units $/ d)(p<0.05)$ (FIG. 4). Plasma biotin concentrations of patients with partial seizures with elementary symptomatology were lower than, but

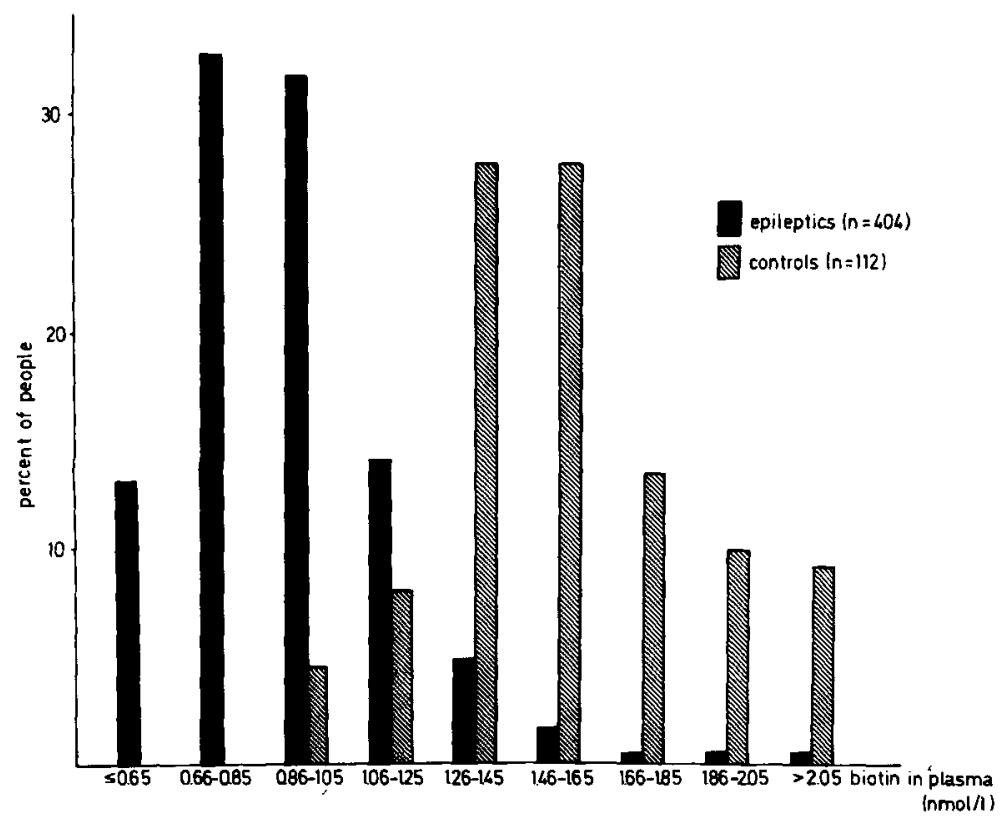

FIGURE 2. Distribution of plasma biotin concentrations in epileptics and controls. 
did not differ significantly from, those of epileptics with absences without known etiology or with impulsive-petit-mal epilepsy $(0.90 \pm 0.28 \mathrm{nmol} / 1$ compared with 0.98 $\pm 0.30 \mathrm{nmol} / 1$ ).

The biotin concentrations of patients on monotherapy are summarized in FIGURE 5. Whereas no significant differences were found between the values of patients treated with primidone, carbamazepine, phenytoin, or phenobarbital, the levels in epileptics treated with sodium valproate alone were significantly higher. A probable negative correlation between plasma biotin levels and serum concentrations of anticonvulsants in patients under monotherapy resulted only for the phenytoin group (correlation coefficient $\mathrm{r}=-0.295,0.1>p>0.05$ ). The 6 patients with the highest phenytoin serum levels $(15.0-22.8 \mu \mathrm{g} / 1)$ had very low biotin concentrations of less than 0.82 $\mathrm{nmol} / \mathrm{l}$.

Evaluation of the relationship between average daily dose of anticonvulsants in equivalent units per day and biotin plasma concentrations in all 404 epileptics resulted in a weak negative correlation $(r=-0.0754,0.1>p>0.05)$. The group of epileptics with a high average daily dose of anticonvulsants ( $>10$ equivalent units per day; $n=$ $84)$ showed significantly $(p<0.0025)$ lower plasma biotin concentrations $(0.88 \pm 0.25$ $\mathrm{nmol} / \mathrm{l})$ than the group with a low dose ( $<5$ equivalent units per day; $\mathrm{n}=71,0.97 \pm$ $0.28 \mathrm{nmol} / \mathrm{l}$ ) (FIG. 6).

The plasma biotin concentration in 80 epileptics with at least one symptom of

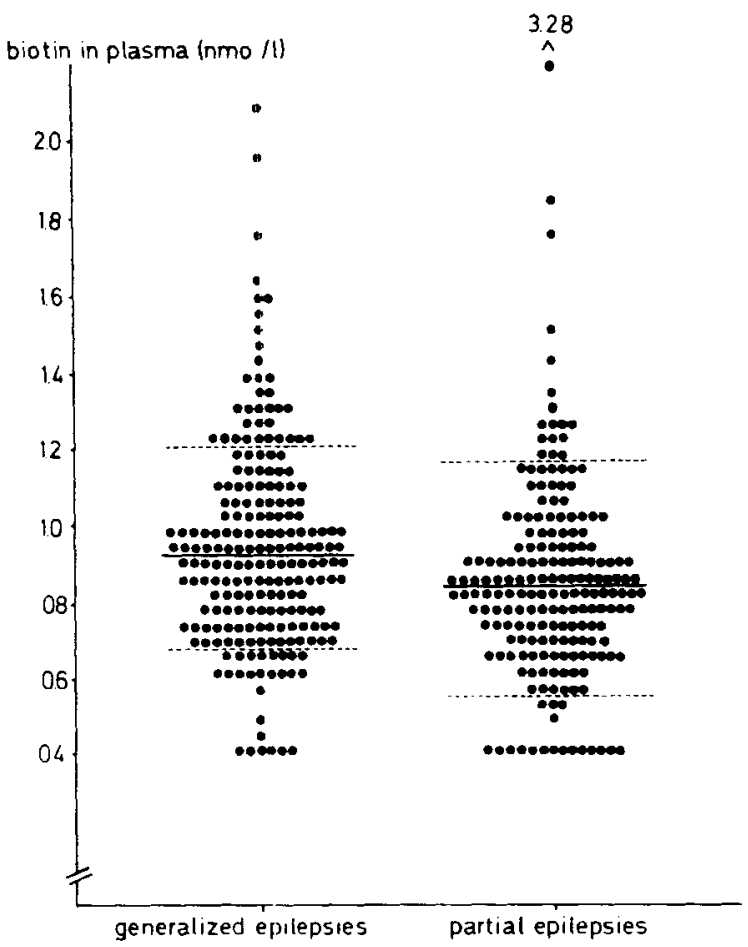

FIGURE 3. Plasma biotin concentrations of patients with generalized and partial epilepsies $(-=$ mean value, -..- = standard deviation). 


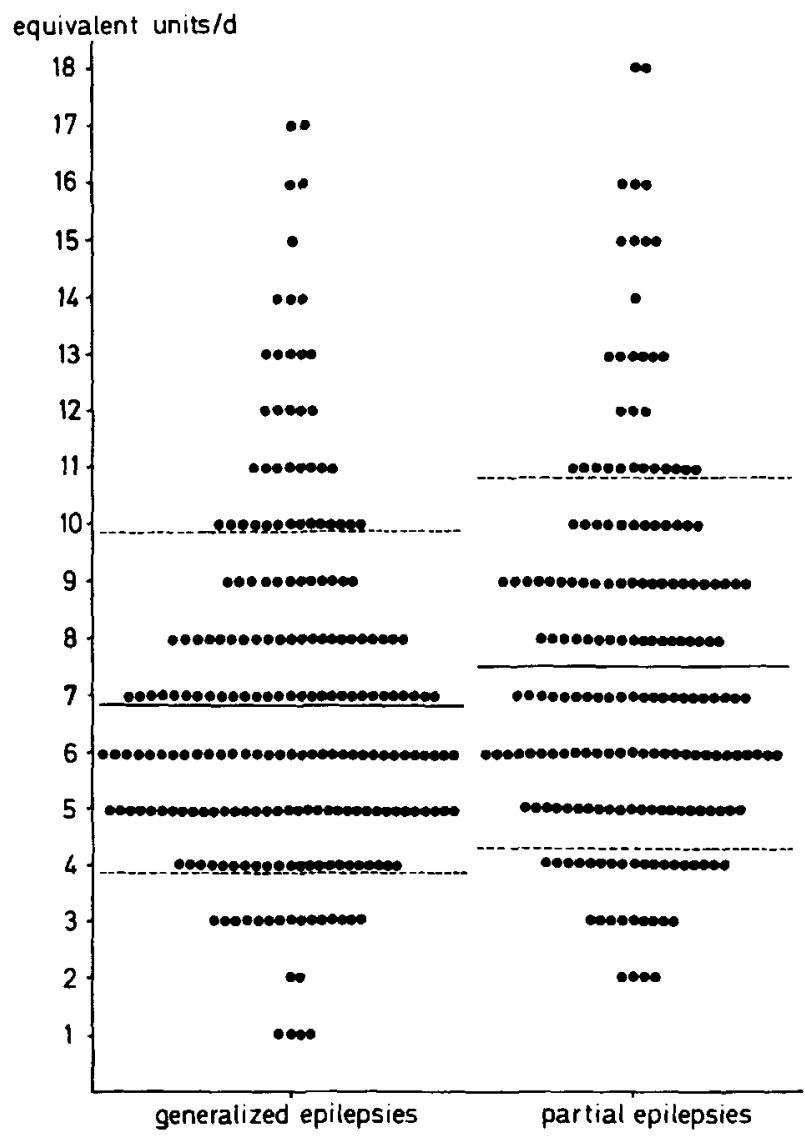

FIGURE 4. Average daily intake of anticonvulsants in patients with generalized and partial epilepsies $(--=$ mean value; $---\cdot-=$ standard deviation $)$.

cerebellar dysfunction (nystagmus, ataxia, cerebellar dysarthria) was $0.83 \pm 0.23$ $\mathrm{nmol} / 1$ and differed significantly from that of the other epileptics $(0.92 \pm 0.29 \mathrm{nmol} / \mathrm{l})$ $(p<0.01)$. Eighty-five percent of the epileptics with cerebellar dysfunction had plasma biotin concentrations $<1.02 \mathrm{nmol} / 1$ compared with 73.8 percent of the others (FIG. 7). Dermatological disturbances like exfoliative dermatitis were not seen in our patients. Sixty-three epileptics suffered from acne, 26 from milder forms of eczematous dermatitis. The average biotin concentrations of these patients and the other epileptics are given in TABLE 1; the values did not differ significantly.

\section{BIOTIN PLASMA CONCENTRATIONS BEFORE AND AFTER STARTING ANTICONVULSANT THERAPY}

To evaluate the effect of an anticonvulsant medication on biotin levels, plasma concentrations have to be measured in patients with newly recognized epilepsy before 


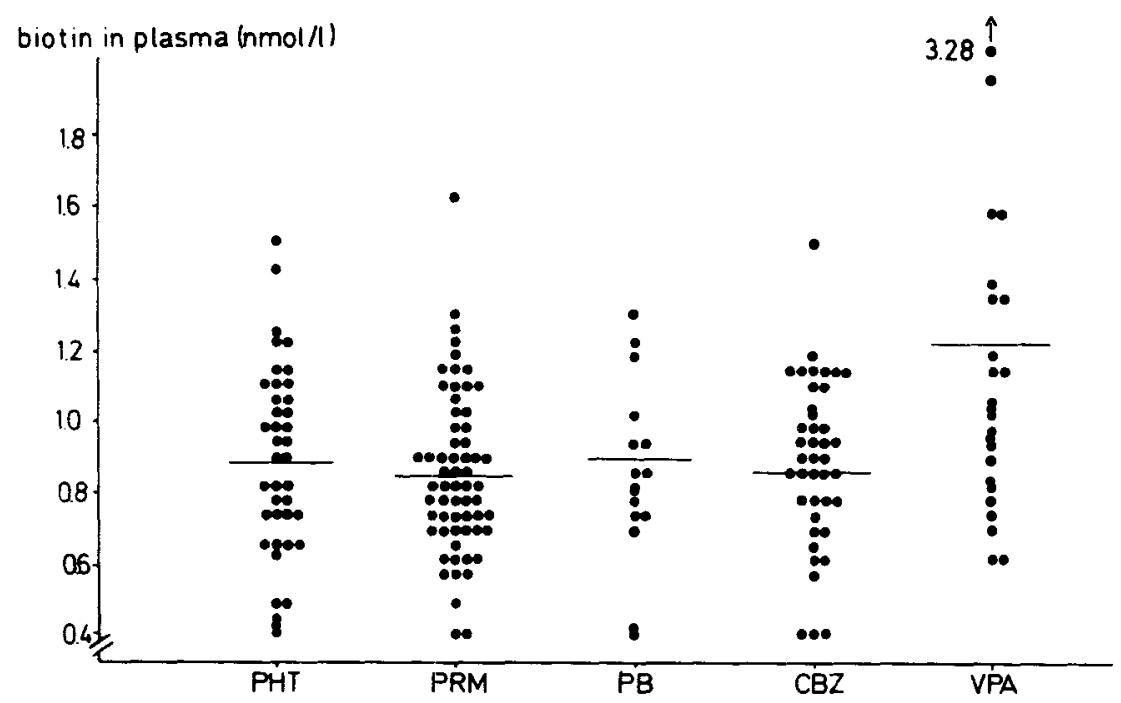

FIGURE 5. Plasma biotin concentrations in epileptics under monotherapy (PHT = phenytoin, PRM = primidone, $\mathrm{PB}=$ phenobarbital, $\mathrm{CBZ}=$ carbamazepine, $\mathrm{VPA}=$ sodium valproate $;-=$ mean value).

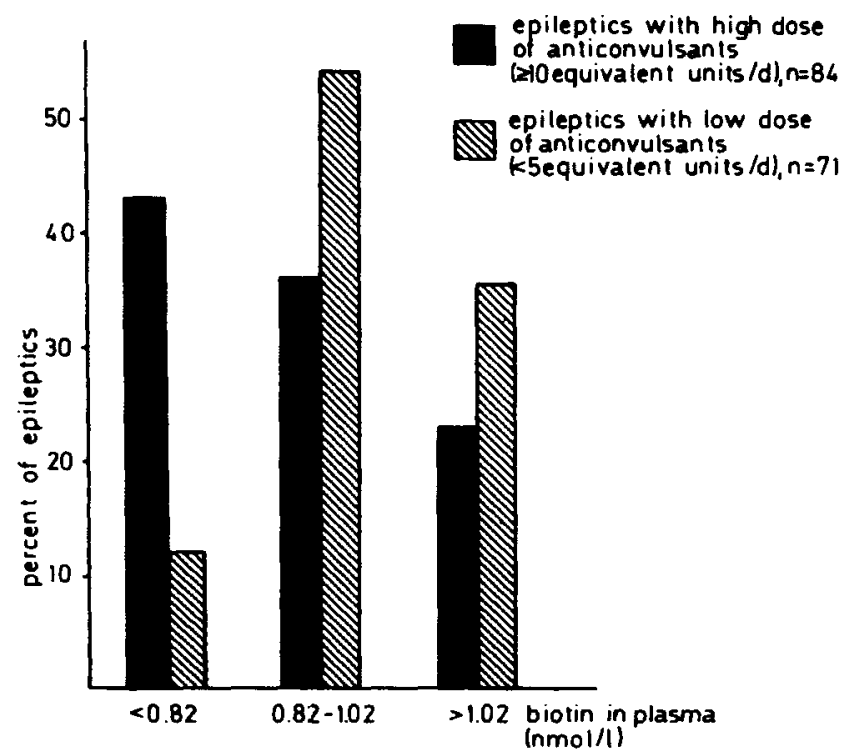

FIGURE 6. Distribution of plasma biotin concentrations in epileptics with high and low mean daily dose of anticonvulsants. 


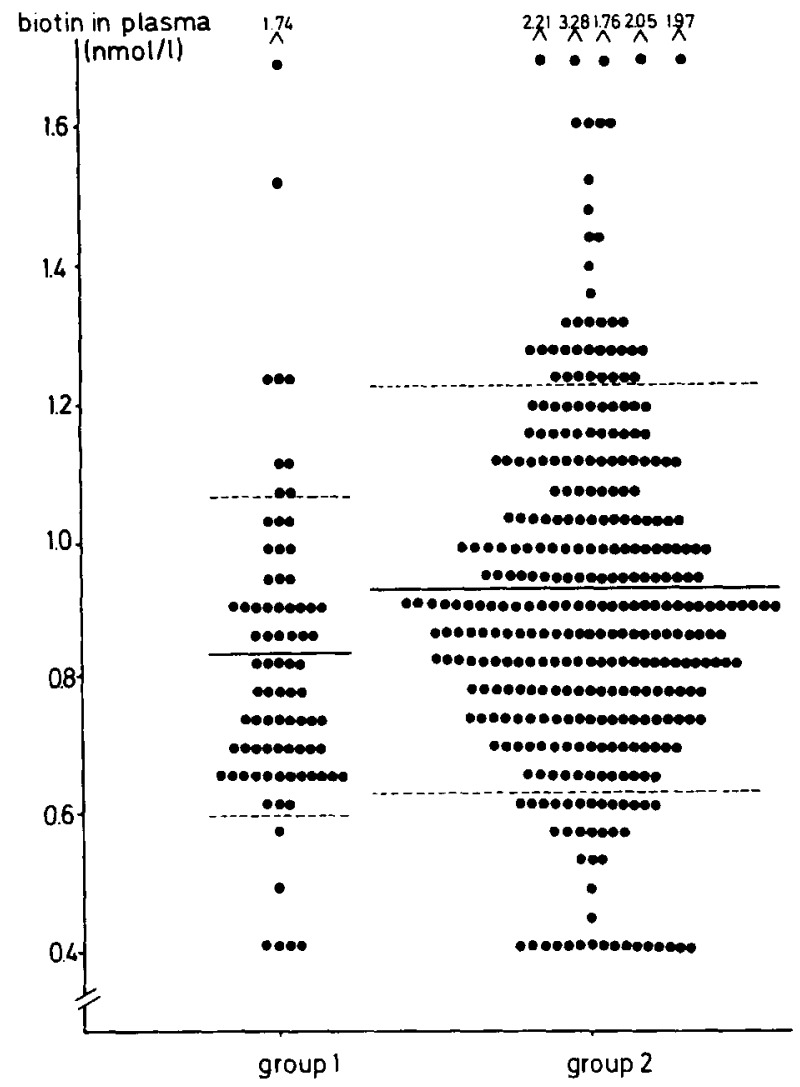

FIGURE 7. Plasma biotin concentration in epileptics with (group 1) and without (group 2) signs of cerebellar dysfunction ( $-=$ mean value; ----- = standard deviation).

the start of anticonvulsant therapy and thereafter. Up to now we have had the opportunity to follow 3 patients in this way.

\section{Patients and Methods}

Patient 1 was a 61-year-old man with an ischemic infarction of the left posterior lobe, verified by cerebral computertomography, and which was caused by angiographi-

TARLE 1. Concentrations of Biotin ( $\overline{\mathrm{x}} \pm$ s.d.) in Plasma of Epileptics with Acne or Eczematous Dermatitis and in Patients without Dermatological Signs

\begin{tabular}{lrc}
\hline & $\mathrm{n}$ & $\begin{array}{c}\text { Biotin in Plasma } \\
(\mathrm{nmol} / \mathrm{l})\end{array}$ \\
\hline Acne & 63 & $0.87 \pm 0.38$ \\
Eczematous dermatitis & 26 & $0.91 \pm 0.25$ \\
Other epileptics & 315 & $0.91 \pm 0.27$ \\
\hline
\end{tabular}


cally evaluated marked stenosis of the left posterior cerebral artery. There was a diabetes mellitus as additional risk factor. One year after the cerebral insult a generalized tonic clonic seizure with a right focal beginning occurred; as no unexpected changes in computertomography were seen, this seizure was classified as the first sign of a vascular epilepsy. The patient was given $3 \times 100 \mathrm{mg}$ phenytoin per day.

Patient 2 was a 42-year-old woman, who had two generalized tonic clonic seizures, beginning with left-sided partial seizures of elementary symptomatology 5 years after ablatio mammae because of carcinoma solidum simplex. Computer tomography showed a cerebral metastasis localized in the right precentral region. Treatment with $3 \times 100 \mathrm{mg}$ phenytoin per day was initiated.

Patient 3 had two generalized tonic clonic seizures after lack of sleep at the age of 25. The electroencephalogramm showed bilateral synchronous spike waves under hyperventilation; the cranial computertomography was normal. A genuine epilepsy was diagnosed. Anticonvulsant therapy with $3 \times 250 \mathrm{mg}$ primidone per day was started. Plasma biotin concentrations were determined in samples taken before and up to 6 months after the start of therapy.

\section{Results}

Plasma biotin concentrations of the three patients are shown in FIGURE 8. Before starting anticonvulsant medication no patient had a low biotin level. In all patients the

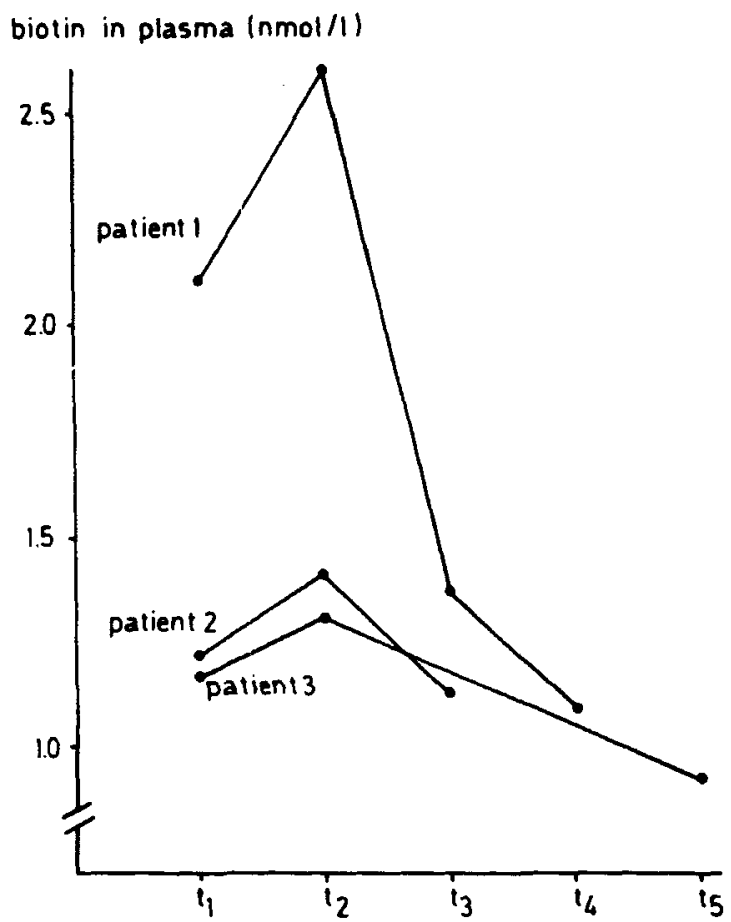

FIGURE 8. Plasma biotin concentrations of 3 epileptics before $\left(t_{1}\right)$ and after $\left(t_{2}=1\right.$ week, $t_{3}=8$ weeks, $t_{4}=16$ weeks, $t_{5}=26$ weeks) start of anticonvulsant therapy. 


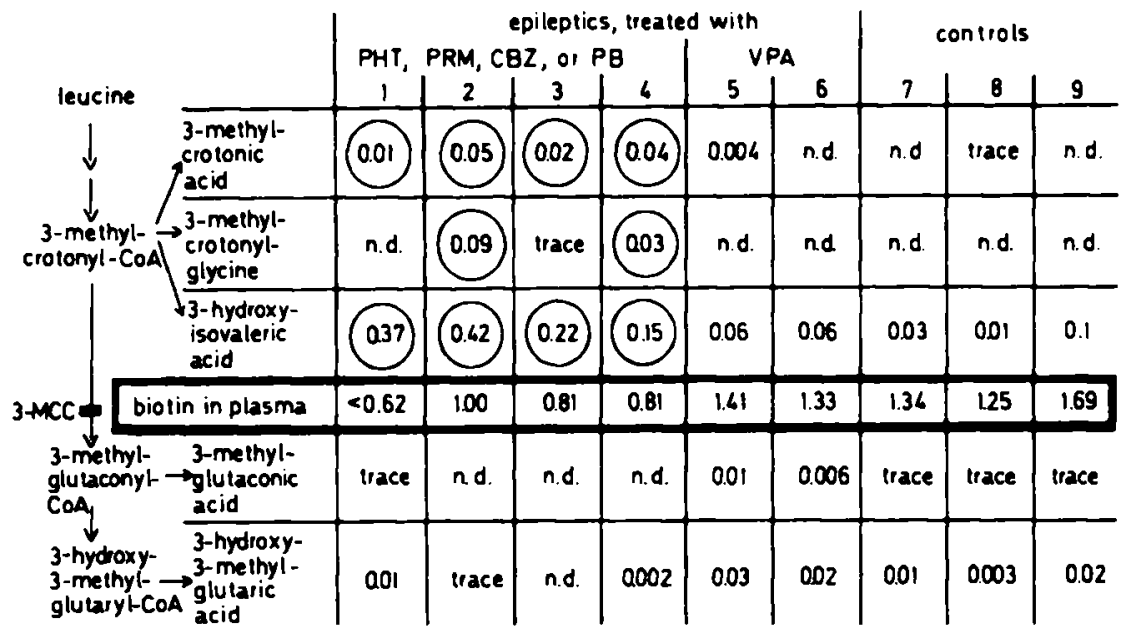

FIGURE 9. Urinary organic acid concentrations $(\mu \mathrm{mol} / \mathrm{mg}$ creatinine, n.d. $=$ not detectable, circled - clevated concentrations) resulting from leucine catabolism (3-MCC - 3-methylcrotonyl-CoA carboxylase) and plasma biotin concentrations in six epileptics [four treated with phenytoin (PHT), primidone (PRM), carbamazepine (CBZ) or phenobarbital (PB), two with sodium valproate (VPA)] and in three controls.

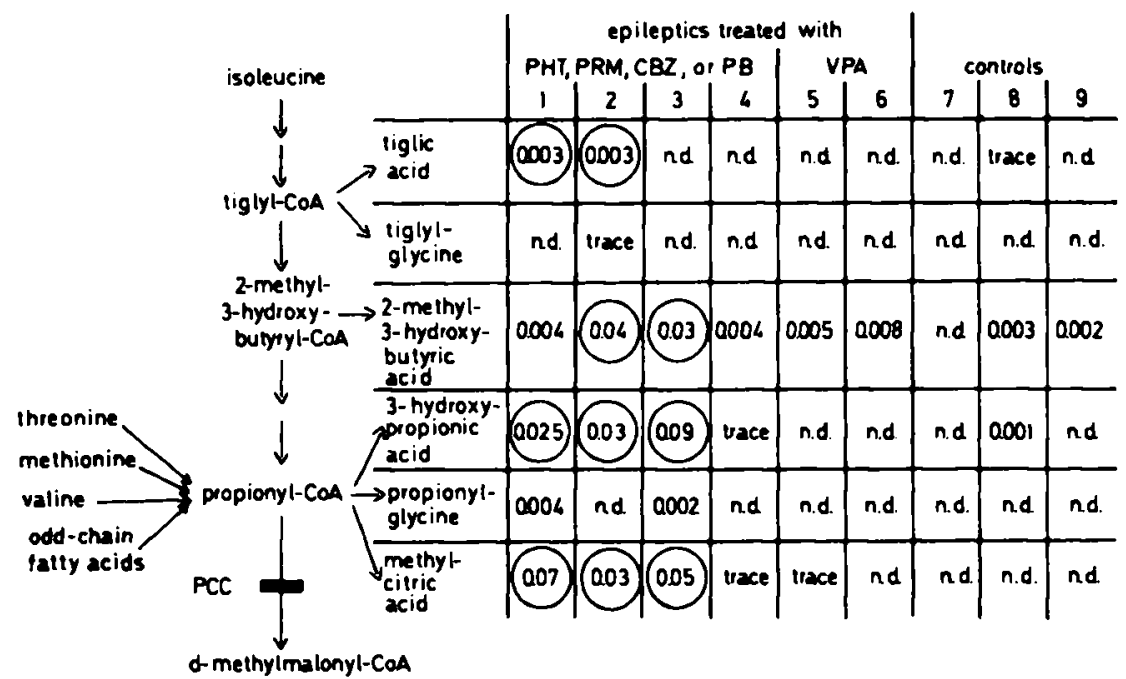

FIGURE 10. Urinary organic acid concentrations $(\mu \mathrm{mol} / \mathrm{mg}$ creatinine, n.d. $=$ not detectable, circled - elevated concentrations) resulting from catabolism of isoleucine, valine, methionine, threonine and odd-chain fatty acids (PCC - propionyl-CoA carboxylase) in six epileptics (see FIG. 9) and in three controls. 
biotin concentration increased during the first week of therapy, and fell below the starting level in the following weeks. In patient 3, after half a year on antiepileptic treatment, a subnormal biotin concentration of less than $0.92 \mathrm{nmol} / \mathrm{l}$ was determined.

\section{BIOTIN-DEPENDENT ORGANIC ACIDS IN THE URINE OF EPILEPTICS UNDERGOING LONG-TERM TREATMENT}

One of the most important criteria for the diagnosis of an inborn error of biotin-dependent carboxylases ${ }^{9}$ or dietary deficiency of biotin ${ }^{10,11}$ is the detection of defined organic acids in urine, known to be elevated in biotin deficiency. Typically, a reduced activity of 3-methyl-crotonyl-CoA carboxylase leads to an elevated excretion of 3-methylcrotonic acid, of its product of hydration (3-hydroxyisovaleric acid), and of 3-methylcrotonylglycine formed by conjugation with glycine (see FIG. 9). An increased excretion of 3-hydroxypropionic acid, propionylglycine and methylcitric acid is caused by a reduced activity of propionyl-CoA carboxylase; further metabolites, which may be elevated when the activity of this carboxylase is deficient, are tiglic acid, tiglylglycine and 2-methyl-3-hydroxybutyric acid, derived from the catabolism of isoleucine (see FIG. 10). Elevation of lactic acid, which is in balance with pyruvic acid, has been described as a typical pattern in a deficiency of pyruvate carboxylase activity. If the reduced levels of biotin found in epileptics cause a decrease in the activity of biotin-dependent carboxylases, then abnormal organic acids should be detected in the urine of patients on chronic anticonvulsant therapy.

\section{Patients and Methods}

Twenty-four hour urine samples were collected from 6 male epileptics, aged 22 to 37 years, who had been under anticonvulsant treatment for at least one year. Organic acids were determined as trimethylsilyl derivatives by combined gas-chromatography and mass spectroscopy. ${ }^{12}$ Type of seizures and serum levels of anticonvulsants given at the time of examination are compiled in TABLE 2. Blood was taken for microbiological determination of biotin in plasma on the morning after collection of 24 -h urine. Three healthy persons ( 2 men, 30 and 34 years old, 1 woman, 27 years old) served as controls.

\section{Results}

In the four epileptics treated with phenytoin, primidone, carbamazepine or phenobarbital elevated concentrations of at least two of the three metabolites were found (FIG. 9), which are known to occur due to a deficiency of 3-methylcrotonyl-CoA carboxylase. The concentrations of the two acids, which appear after the carboxylation step in the catabolism of leucine, were lower in the urines of these four epileptics compared with the concentrations in the other urines. Furthermore, the plasma biotin concentrations were markedly lower in the four epileptics treated with phenytoin, primidone, carbamazepine or phenobarbital than in the two patients treated with sodium valproate, or in the three controls. At least three of the metabolites, which can be increased in a deficiency of propionyl-CoA carboxylase activity, were elevated in the urines of three of the four epileptics treated with other anticonvulsants than sodium valproate (FIG. 10), whereas the levels of these compounds were normal in the 


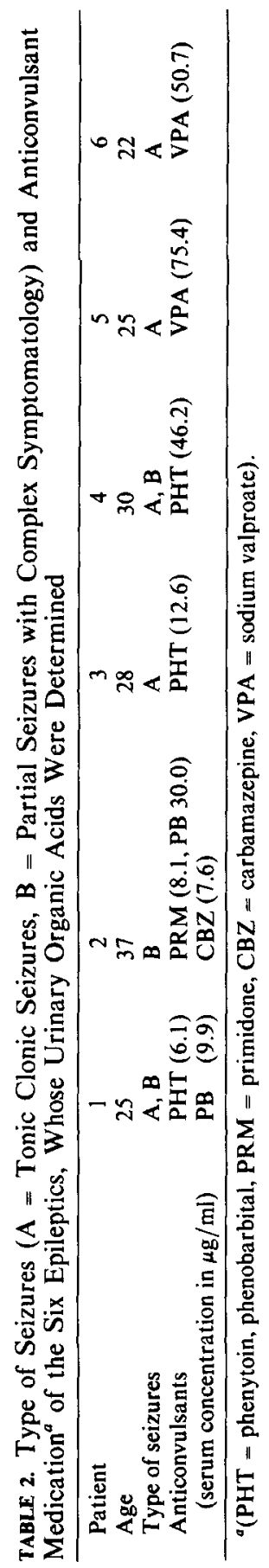


epileptics under sodium valproate and in controls. Lactate concentrations in the urines of the four epileptics not treated with sodium valproate were markedly higher than in the other subjects (FIG. 11).

\section{LACTATE IN PLASMA OF EPILEPTICS UNDERGOING LONG-TERM TREATMENT}

Deficiency of pyruvate carboxylase activity can also lead to an elevation of plasma lactate levels. Therefore, the plasma lactate concentrations were determined in some long-term treated epileptics and compared with those of a control group.

\section{Patients and Methods}

Thirty-seven epileptics ( 24 men, 13 women) of the Heidelberg outpatient clinic for epileptics, aged 20 to 42 years, were investigated. The patients were treated for at least one year with anticonvulsants, mostly in combination therapy. The controls were 16 healthy persons ( 9 men, 7 women) aged 20 to 46 years, who took no medication. After short compression for 30 seconds, $2 \mathrm{ml}$ venous blood was taken from the fasting subjects. The blood was mixed immediately with 2 drops fluoride/EDTA. Lactate was determined using an enzymatic test in modification of the method described by Noll. ${ }^{13}$ The lactate concentrations of the two groups were compared using Student's t-test.

\section{Results}

The epileptics undergoing long-term treatment had a mean plasma lactate concentration of $1.32 \pm 0.44 \mathrm{mmol} / 1$, which was higher than that found in controls $(1.05 \pm 0.32 \mathrm{mmol} / \mathrm{l} ; p<0.05)$. The individual levels are given in Figure 12 .

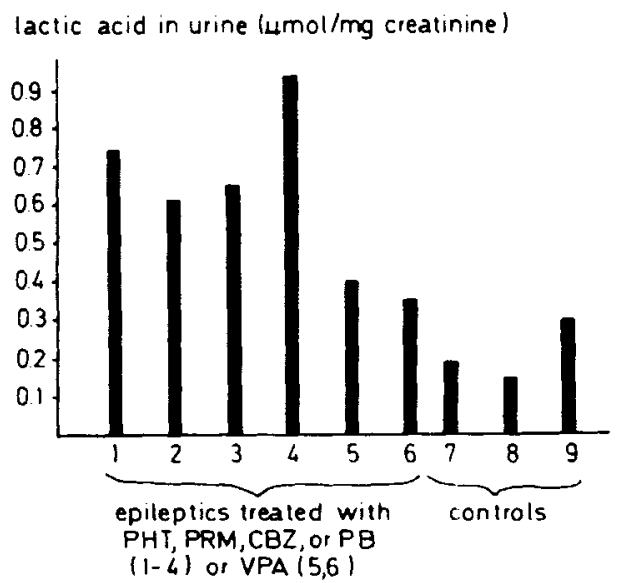

FIGURE 11. Lactic acid concentration in urine of six epileptics (see FIG. 9) and in three controls. 


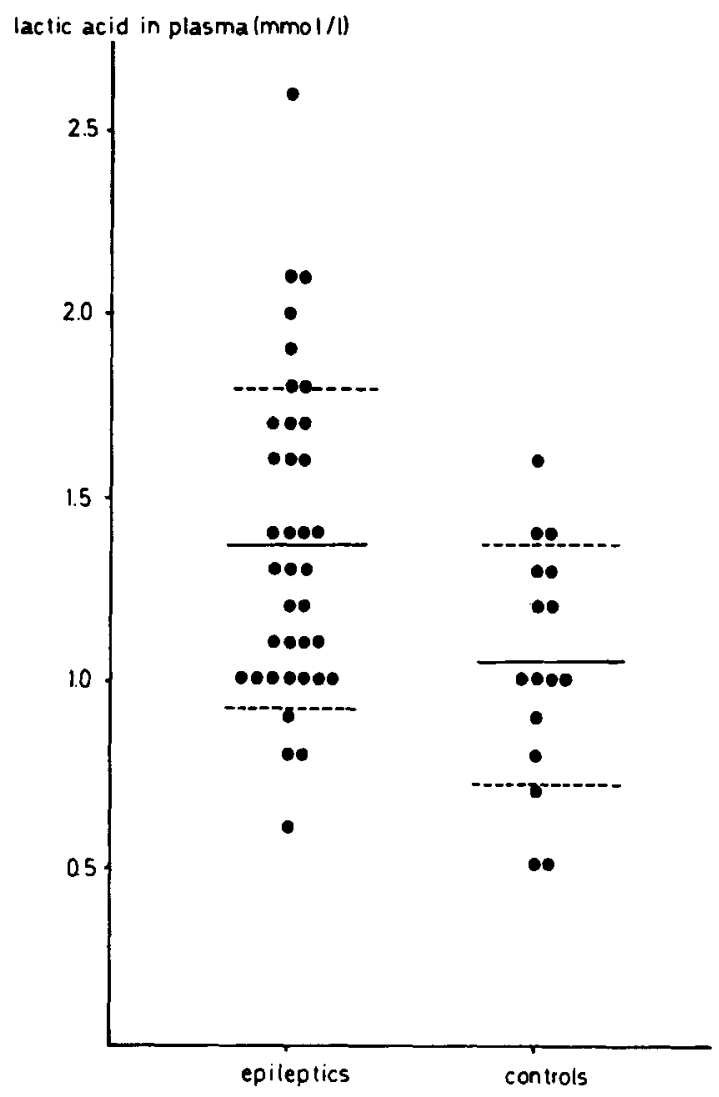

FIGURE 12. Concentration of lactic acid in plasma of 37 long-term treated epileptics and 16 controls $(-=$ mean value;...-- standard deviation $)$.

\section{DISCUSSION}

The presented results illuminate some interesting aspects of the relationship between biotin status and anticonvulsant therapy in epileptics. The plasma biotin concentrations of epileptics under long-term treatment with anticonvulsants are markedly reduced. The degree of biotin reduction clearly exceeds that of other vitamin deficiencies seen in chronic anticonvulsant therapy e.g. of folate or 25 -hydroxycholecalciferol. ${ }^{14}$ The plasma biotin concentrations of patients under monotherapy with sodium valproate are higher than those of epileptics treated with other anticonvulsants. This finding seems to be of interest since valproate differs chemically from the other anticonvulsants and from biotin.

It seems that the observed reduction of biotin levels is caused by the intake of anticonvulsant and is not a sign of the underlying disease itself. The biotin concentration of some untreated epileptics was normal and epileptics suffering from generalized epilepsies, who should a priori have a higher genetic disposition than those with partial epilepsies, showed a higher mean biotin concentration than the latter. 
The fact that there was a higher mean intake of anticonvulsants in partial epilepsy, confirms the assumption that the reduction of biotin levels is a drug effect. The negative correlation approaching significance between the average daily intake of anticonvulsants and the plasma biotin concentrations and the significantly higher biotin concentrations found in epileptics with a low average daily intake of anticonvulsants further confirm the effect of anticonvulsants on biotin status.

At this time only speculations on the mechanism for the reduction of biotin levels in epileptics are possible. The initial increase in plasma biotin concentration, observed in patients after starting anticonvulsant therapy, could be due to a blockage in the uptake of biotin into human tissues or due to a release of biotin from stores by anticonvulsants. Further investigations will show whether competitive interactions, disturbances in absorption, hepatic induction of enzymes catabolizing or consuming biotin, or influences on the enteral biotin synthesis play a role in the reduction of biotin levels by anticonvulsants.

The reduced biotin status seen in epileptics has a biochemical effect in elevating the concentration of certain organic acids in blood and urine. Previously, such an increase was only known to occur in children with an inborn error of biotin-dependent enzymes and in children with a dietary biotin deficiency."

The reduction of biotin levels could be a factor in the mode of action of anticonvulsants: a reduced activity of biotin-dependent carboxylases could result in a higher cerebral concentration of free carbon dioxide, a mechanism, which would elevate the seizure threshold. Especially pyruvate carboxylase is known to be the essential enzyme for fixing carbon dioxide in the brain..$^{15}$ If the concentration of carbon dioxide is too elevated, the seizure threshold will finally fall under the starting level. ${ }^{16,17}$ This mechanism could explain the seizures seen in phenytoin intoxication ${ }^{18,19}$ and in inborn errors of biotin-dependent enzymes. Accordingly no beneficial effects with the exception of sodium valproate ${ }^{20}$ have been described when affected children were given anticonvulsants. ${ }^{21-24}$ Only in one patient with a non-biotin-dependent isolated defciency of pyruvate carboxylase activity were phenobarbital, phenytoin and diazepam, found to have some benefit. ${ }^{25} \mathrm{~A}$ reduced pyruvate carboxylase activity can lead to a decrease of oxalacetate, which is essential for the de novo synthesis of aspartate. ${ }^{26}$ Aspartate is known to be an excitatory neurotransmitter, and decreased concentrations have been found in some areas of the brain of animals when given phenytoin. ${ }^{27}$ This could be a further biotin-dependent mechanism in the mode of action of anticonvulsants. Furthermore, oxalacetate is a key intermediate in the tricarboxylic acid cycle ${ }^{28}$ and is assumed to play a very important role in the anaplerotic metabolism of the brain. ${ }^{29}$ It seems therefore possible, that a deficiency of pyruvate carboxylase activity could additionally lower the seizure threshold via blocking the energy production in the citrate cycle. Furthermore, an elevation of the inhibitory neurotransmitter glycine can be postulated as possible consequence of reduced biotin levels: as a decreased activity of pyruvate carboxylase, which is essential for the catabolism of serin and consequently of glycine, or of propionyl-CoA carboxylase, via the metabolism of methionine and threonine, could elevate glycine levels. ${ }^{7}$

The reduced biotin levels could play a role in some well-known side effects of anticonvulsants, such as the cerebellar disturbances often described as a symptom in nutritional biotin deficiency or in patients with a deficient activity of biotin-dependent carboxylases. ${ }^{9}$ In our sample lower mean biotin concentrations were found in patients with cerebellar signs than in the other epileptics, and this may be seen as an indication of a possible causal relationship. For the same reason other authors postulated a connection between the reduced levels of folate and the ataxia caused by anticonvulsants. ${ }^{30}$ The serum phenytoin concentrations are known to correlate strongly with the appearance and the degree of cerebellar symptoms; ${ }^{31,32}$ and only the serum levels of this 
anticonvulsant showed a negative correlation with the plasma biotin concentrations which almost reached significance. Whereas cerebellar symptoms as sign of an overdose of phenytoin, carbamazepine, and not so often of primidone or phenobarbital, ${ }^{33}$ can occur at any time of a long-term anticonvulsant treatment and may also persist in some cases, ${ }^{34-36}$ an exfoliative dermatitis is described as a severe allergic reaction only during the first weeks of anticonvulsant medication with the consequence of discontinuing the drug. ${ }^{37}$ Therefore, it is not surprising that in our group of long-term treated epileptics no patients with exfoliative dermatitis were detected. As in nonepileptic subjects, ${ }^{8}$ no difference in mean biotin levels was noted in epileptics with and without other dermatologic manifestations (acne or eczematous dermatitis).

Further research is needed to verify possible correlations between biotin status and findings in treated epileptics such as elevated cholesterol levels ${ }^{38}$ also reported in cases of pyruvate carboxylase deficiency ${ }^{25}$ as well as in nutritional biotin deficiency, ${ }^{39,40}$ or disturbances of the immunoregulatory system, noted in inborn errors of metabolism of biotin-dependent carboxylases. ${ }^{41-43}$ Furthermore, the teratogenic effect of biotin deficiency in animals ${ }^{44}$ might be connected to the teratogenicity of anticonvulsants and deserves further attention.

\section{SUMMARY}

Microbiologically determined plasma biotin levels in 404 epileptics under longterm treatment with anticonvulsants were markedly lower than in 112 controls $(p<$ 0.0005 ). Patients with partial epilepsy had lower biotin levels and higher average daily intake of $\mathrm{AC}$ than those with generalized epilepsy. Epileptics treated with valproate sodium in monotherapy showed considerably higher biotin levels than epileptics with monotherapy of primidone (PRM), carbamazepine (CBZ), phenytoin (PHT) or phenobarbital (PB). The group of epileptics with high average daily dose of anticonvulsants had lower biotin levels than the group with low dose. In three patients with newly recognized epilepsy biotin levels were normal before starting anticonvulsant medication, increased during the first week and fell under the starting level in the following weeks. Four epileptics treated with PHT, PB, PRM or CBZ had an increased urinary excretion of organic acids, as found in patients with a deficiency of biotin-dependent carboxylases. In 37 epileptics undergoing long-term treatment plasma lactate concentrations were determined; they had a higher mean concentration than that found in controls. Our results suggest, that the lowering of biotin in epileptics (1) is caused by intake of anticonvulsants and (2) has a biochemical effect in these patients. It is discussed, whether this could be a factor in the mode of action of anticonvulsants.

\section{REFERENCES}

1. Johnston, D. \& G. E. Slater. 1982. Valproate, Mechanism of action. In Antiepileptic drugs. D.M. Woodbury, J.K. Penry \& E.C. Pippenger, Eds. Raven Press. New York. pp. 611-616.

2. ReYNOLDS, E. H. 1976. Folate and epilepsy. In Biochemistry and Neurology. H.F. Bradford \& C.-D. Marsden, Eds. Academic Press. London, New York, San Francisco. pp. 247-252.

3. CASPERS, H. \& E. J. SPECKMANN. 1969. DC potential shifts in paroxysmal states. In Basic Mechanisms of the Epilepsies. H.H. Jasper, A.A. Ward \& A. Pope, Eds. Little, Brown \& Co. Boston. pp. 375-388.

4. Krause, K.-H., P. Berlit \& J.-P. Bonjour. 1982. Erniedrigung des Biotins als möglicher 
Faktor im Wirkmechanismus von Antiepileptika. Arch. Psychiatr. Nervenkr. 231: 141148.

5. Krause, K. H., P. Berlit \& J.-P. Bonjour. 1982. Impaired biotin status in anticonvulsant therapy. Ann. Neurol. 12: 485-486.

6. Frigg, M. \& G. Brubacher. 1976. Biotin deficiency in chicks fed a wheat based diet. Int. J. Vit. Nutr. Res. 46: 314-321.

7. KRAUSE, K.-H. 1983. Biotin-Erniedrigung unter antiepileptischer Behandlung. Ein Beitrag zur möglichen Wirkungsweise von Antikonvulsiva. Hochschul-Verlag, Freiburg.

8. BonJour, J.-P. 1977. Biotin in man's nutrition and therapy-a review. Int. J. Vit. Nutr. Res. 47: 107-118.

9. Bonjour, J.-P. 1981. Biotin-dependent enzymes in inborn errors of metabolism in humans. Wld. Rev. Nutr. Diet. 38: 1-88.

10. Mock, D. M., A. A. De Lorimer, W. M. LiebmanN, L. Sweetman \& H. Baker. 1981. Biotin deficiency. An unusual complication of parenteral alimentation. N. Engl. J. Med. 304: 820-823.

11. Sweetman, L., L. Suhr, H. Baker, R. M. Peterson \& W. L. Nyhan. 1981 . Clinical and metabolic abnormalities in a boy with a dietary deficiency of biotin. Pediatrics 68: $553-$ 558.

12. Krause, K.-H., W. Kochen, P. Berlit \& J.-P. Bonjour. 1984. Excretion of organic acids associated with biotin deficiency in chronic anticonvulsant therapy. Int. J. Vit. Nutr. Res. 54: $217-222$.

13. NolL, F. 1974. L-Lactat. Bestimmung mit LDH, GPT und NAD. In Methoden der enzymatischen Analysen, 3rd edit. H.U. Bergmeyer, Ed. Verlag Chemie. Weinheim. Vol. 3: $152 \mathrm{I}-1526$.

14. Krause, K.-H., P. Berlit, J.-P. Bonjour, H. Schmidt-Gayk, B. Schellenberg \& J. GILLEN. 1982. Vitamin status in patients on chronic anticonvulsant therapy. Int. J. Vit. Nutr. Res. 52. 375-385.

15. PATEL, M.S. 1974. The relative significance of $\mathrm{CO}_{2}$-fixing enzymes in the metabolism of rat brain. J. Neurochem. 22: 717-724.

16. WOODBURY, D. M. \& R. KARLER. 1960. The role of carbon dioxide in the nervous system. Anesthesiology 21: 686-703.

17. Woodbury, D. M., L. T. Rollins, M. D. Gardner, W. L. Hirschi, J. R. Hogan, M. L. Rallison, G. S. TANNER \& D. A. Brodie. 1958. Effects of carbon dioxide on brain excitability and electrolytes. Am. J. Physiol. 192: 79-90.

18. Woodeury, D. M. 1980. Phenytoin: Proposed mechanisms of anticonvulsant action. In Antiepileptic Drugs: Mechanisms of Action. G.H. Glaser, J.K. Penry \& D.M. Woodbury, Eds. Raven Press. New York. pp. 447-471.

19. Glaser, G. H. 1972. Diphenylhydantoin toxicity. In Antiepileptic Drugs. D.M. Woodbury, J.K. Penry \& R.P. Schmidt. Eds. Raven Press, New York. pp. 219-226.

20. Wolf, B., E. P. Paulsen \& F. E. Dreifuss. 1981. Valproate in the treatment of seizures associated with propionic acidemia. Pediatrics 67: 162-163.

21. Lehnert, W., H. Niederhoff, A. Junker, H. Saule \& W. Frasch. 1979. A case of biotin-responsive 3-methyl-crotonylglycin- and 3-hydroxyisovaleric aciduria. Eur. J. Pediatr. 132: 107-114.

22. Paulsen, E. P. \& Y. E. HsiA. 1974. Asymptomatic propionic acidemia: Variability of clinical expression in a Mennonite kindred. Am. J. Hum. Genet. 26: 66A.

23. Sweetman, L., W. L. Nyhan, N. A. Sakati, A. Ohlsson, M. S. Mange, R. B. Boychuk \& R. KAYE. 1982. Organic aciduria in neonatal multiple carboxylase deficiency. J. lnher. Metab. Dis. 5: 49-53.

24. Thoene, J., H. BaKer, M. Yoshino \& L. Sweetman. 1981. Biotin-responsive carboxylase deficiency associated with subnormal plasma and urinary biotin. N. Engl. J. Med. 304: 817-820.

25. De Vivo, D. C., M. W. Haymond, M. P. Leckie, Y. L. Bussmann, D. B. McDougal \& A.S. Pagliara. 1977. The clinical and biochemical implications of pyruvate carboxylase deficiency. J. Clin. Endocr. Metab. 45: 1281-1296.

26. Achuta Murthy, P. N. \& S. P. Mistry. 1977. Biotin. Prog. Food Nutr. Sci. 2: 405-455.

27. Patsalos, P. N. \& P. T. LASCElles. 1981. Changes in regional brain levels of amino acid 
putative neurotransmitters after prolonged treatment with the anticonvulsant drugs diphenylhydantoin, phenobarbitone, sodium valproate, ethosuximide, and sulthiame in the rat. J. Neurochem. 36: 688-695.

28. BLASS, J. P. 1979. Disorders of pyruvate metabolism. Neurology 29: 280-286.

29. SANDER, J. E., S. PACKMANN \& J. J. TOWNSEND. 1982. Brain pyruvate carboxylase and the pathophysiology of biotin-dependent diseases. Neurology 42: 878-880.

30. Munoz-Garcia, D., T. Del Ser, F. Bermejo \& A. Portera. 1982. Truncal ataxia in chronic anticonvulsant treatment. Association with drug-induced folate deficiency. J. Neurol. Sci. 55: 305-311.

31. Blank, N. K., R. N. Nishimura \& F. J. SeIl. 1982. Phenytoin neurotoxicity in developing mouse cerebellum in tissue culture. J. Neurol. Sci. 55: 91-97.

32. Iivanainen, M., M. Viukari \& E.-P. Helle. 1977. Cerebellar atrophy in phenytointreated mentally retarded epileptics. Epilepsia 18: 375-386.

33. Meinardi, H. \& L. M. K. Stoel. 1974. Side-effects of antiepileptic drugs. In Handbook of Clinical Neurology. P.J. Vinken \& G.W. Bruyn, Eds. North-Holland, Publishing Comp., Amsterdam. Vol. 15: 705-738.

34. Ghatak, N. R., R. A. Santoso \& W. M. MCKinney. 1976. Cerebellar degeneration following long-term phenytoin therapy. Neurology 26: 818-820.

35. MCLain, L. W., J. T. MARIN \& J. H. Allen. 1980. Cerebellar degeneration due to chronic phenytoin therapy. Ann. Neurol. 7: 18-23.

36. Selhorst, J. B., B. KaufmanN \& S. J. Horwitz. 1972. Diphenylhydantoin-induced cerebellar degeneration. Arch. Neurol. 27: 453-455.

37. SChmidT, D. 1981. Behandlung der Epilepsien. Thieme Verlag, Stuttgart, New York.

38. Berlit, P., K.-H. Krause, C. C. Heuck \& B. Schellenberg. 1982. Serum lipids and anticonvulsants. Acta Neurol. Scand. 66: 328-334.

39. Sydenstricker, V. P., S. A. Singal, A. P. Briggs, N. M. De Vaughn \& H. ISbell. 1942. Observations on the "egg white injury" in man. JAMA 118: 1199-1200.

40. SCOTT, D. 1958. Clinical biotin deficiency ("egg white injury"). Report of a case with some remarks on serum cholesterol. Acta Med. Scand. 162: 69-70.

41. Cowan, M. J., D. W. Wara, S. Packman, A. J. Ammann, M. Yoshino, L. Sweetman \& W. L. NyHAN. 1979. Multiple biotin-dependent carboxylase deficiencies associated with defects in T-cell and B-cell immunity. Lancet ii:115-118.

42. Sander, J. E., N. Malmud, M. J. Cowan, S. Packmann, A. J. Amman \& D. W. Wera. 1980. Intermittent ataxia and immunodeficiency with multiple carboxylase deficiencies: a biotin-responsive disorder. Ann. Neurol. 8: 544-547.

43. Munnich, A., A. Fischer, J. M. Saudubray, C. Griscelli, F. X. Coude, H. Ogier, C. ChARPENTIER \& J. FREZEL. 1981. Biotin-responsive immunregulatory dysfunction in multiple carboxylase deficiency. J. Inher. Metab. Dis. 4: 113-114.

44. Watanabe, T. 1983. Teratogenic effects of biotin deficiency in mice. J. Nutr. 113:574581.

\section{DISCUSSION OF THE PAPER}

H. N. Bhagavan (Hoffmann-La Roche, Inc., Nutley, $N J$ ): Did you see any clinical symptoms due to low biotin status like a dermatitis or loss of hair?

K.-H. KRAUSE: We had proved possible correlations between dermatological signs in our patients. We had acne and milder form of eczema and dermatitis.

BHAGAVAN: Do you recommend biotin supplementation in some of these patients?

KRAUSE: At this time we cannot generally recommend such a supplementation. 